\title{
PEMANFAATAN LIMBAH PELAT BAJA \\ DARI BAHAN SISA PRAKTEK KERJA PELAT \\ MENJADI PRODUK PELAT SIKU PENYANGGA DUDUKAN BUKU MENGGUNAKAN PROSES BENDING DAN EMBOSSING
}

\author{
Suyadi, Ariawan W.P., Poedji Haryanto, Paryono, Sugeng Irianto \\ JurusanTeknikMesinPoliteknikNegeri Semarang \\ Jl. Prof. Soedarto, SH, Tembalang, Semarang 50275 \\ E-mail : suyadimt@yahoo.com
}

\begin{abstract}
Abstrak
Tujuan penelitian ini adalah menaikkan nilai tambah limbah material sisa praktek kerja pelat menjadi produk pelat siku penopang tempat dudukan buku dengan proses bending dan embossing di bengkel teknik mesin Polteknik Negeri Semarang. Salah satu praktek bengkel bagi mahasiswa teknik mesin tingkat 1 dan 2 adalah kerja pelat (Sheet metal) material sisa potongan kerja pelat baja low carbon ini adalah limbah dan biasanya dibuang agar material limbah pelat bisa dimanfaatkan sebagai produk yang mempunyai nilai ekonomi maka perlu dibuatkan alat bantu yang digunakan untuk membentuk pelat siku penyangga dengan proses bending dan embossing, akibat proses embossing pelat siku penyangga meningkat kekuatannya $4900 \%$ dalam menahan beban tekuk/gaya bendingnya.
\end{abstract}

Kata Kunci : Magnesium”, “pelat baja”, “pelat siku”, “bending dan embossing”.

\section{Pendahuluan}

Salah satu praktek bengkel bagi mahasiswa teknik mesin Polines tingkat 1 dan 2 adalah kerja pelat (Sheet metal), material sisa potongan kerja pelat ini adalah limbah dan biasanya dibuang, bila pembuangannya sembarangan atau tempat sampah yang dilingkungan terbuka bisa mencemari tanah dan air, karena limbah potongan pelat ini termasuk logam berat (tergolong B3), selain karena sudah tidak dapat digunakan untuk bahan baku praktek lagi namun material limbah pelat bisa dimanfaatkan untuk dibuat suatu produk yang mempunyai nilai ekonomi dengan cara diproses dengan alat bantu compound tool yang digunakan untuk membentuk pelat siku penyangga dengan proses bending dan embossing.

Produk pelat siku penyangga memerlukan tahapan proses pemotonganan (blanking) dengan alat potong, bending dan embossing dengaan alat bantu bending sekaligus sebagai embossing secara serentak dalam satu proses tekan dan proses terakhir adalah pelobangan (piercing). Produk pelat siku yang sudah jadi perlu diuji kekuatan rusaknya dengan cara memberi beban diatasnya kemudian dibandingkan dengan kekuatan pelat siku yang tidak mengalami proses embossing, daril hasil pengujian pemberian beban dianalisis dan dibandingkan perbedaan kekuatannya. Jadi sasaran capaian pada penelitian ini adalah teknologi tepat guna yang diterapkan pada compound tool untuk memproduksi produk pelat siku penyangga dudukkan buku ( seperti gambar 3). Setelah selesai melakukan penenelitian ini, sampel uji berupa produk pelat siku penyangga diuji kekuatan tekuknya sampai rusak pada gaya sebesar $500 \mathrm{~N}$ bila dibandingkan dengan kekuatan tekuk rusak sampel uji tanpa diembos pada gaya $10 \mathrm{~N}$, dapat disimpulkan bahwa pengaruh proses embossing pada sampel uji pelat siku penyangga dudukan buku mengalami peningkatan 50 kali atau naik $4900 \%$ dari kekuatan sampel uji yang tidak mengalami proses embossing.

\section{Metode Penelitian}

Tahapan penelitian dan semua rangkaian kegiatan akan kami lakukan di Bengkel Fabrikasi Teknik Mesin Politeknik Negeri Semarang. Adapun tahapan penelitian ini sebagai berikut : 


\subsection{Studi Literatur}

Pada studi ini dimaksudkan untuk menggali permasalahan sifat elastis plat baja pada limbah material pelat yamg biasanya dibuang jadi beban lingkungan ternyata bisa dibuat menjadi produk pelat siku yang kaku dengan cara dibending dan diembos.

\subsection{Observasi}

Observsi di lapangan dalam upaya untuk mengidentifikasi sifat plat baja yang kuat dan tidak kaku , maka perlu diupayakan agar kaku dengan pembuatan alat bantu compound tool yang bisa membending dan mengembos.

\subsection{Merancang alat Bantu Compound Tool}

Berdasarkan hasil identifikasi permasalahan dalam proses bending dan embossing perlu dirancang alat yang bisa memproses bending dan embossing yaitu compound tool. (lihat gambar 1.)

\subsection{Pembuatan Alat Alat Bantu Compound Tool}

Pembuatan alat bantu compound too berdasarkan gambar rancangan sebelumnya, tahap pertama membuat pelat bawah, pelat atas, punch holder, punch dan die seusuai rancangan dan tahap kedua merakit komponen-menjadi kesatuan alat compoud tool.

\subsection{Pengujian Hasil Pembuatan Alat Bantu Compound Tool}

Pengujian alat merupakan tolok ukur keberhasilan penelitian, karena tanpa pengujian niscaya penelitiannya belum mencapai tujuannya. Adapun pengujian dilakukan untuk mengetahui berfungsi tidaknya alat bantu compound tool dengan baik, pengujian ini dilakukan dengan menguji kebutuhan gaya tekan bending dan embossingnya sampai sampel uji menjadi produk pelat siku penyangga setelah itu sampel uji yang telah menjadi siku penyangga diuji seberapa besar beban maksimal yang mampu disangga.

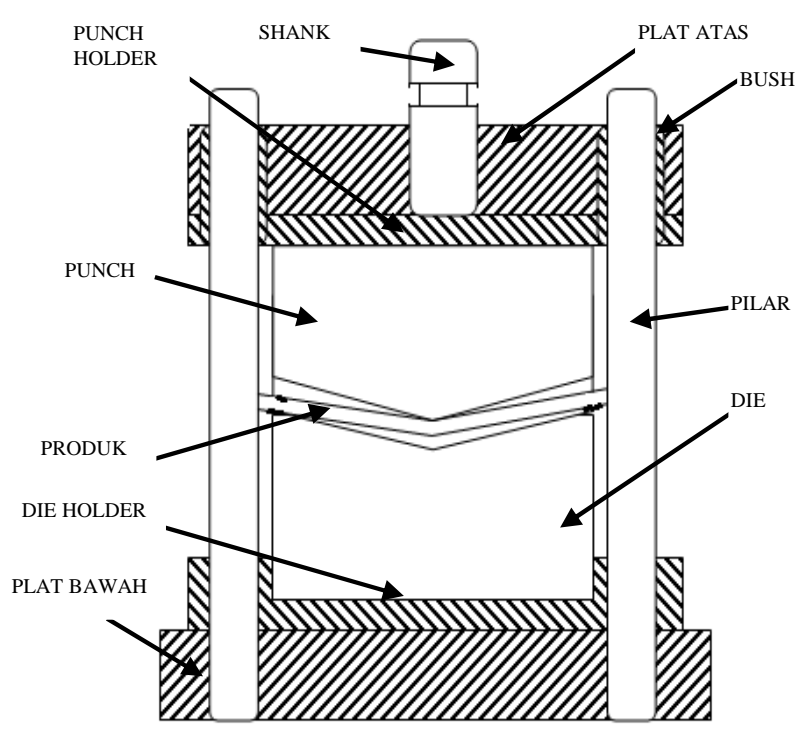

Gambar 1. Rancangan Alat bantu compound tool

\section{Gambar 2. Bahan baku pelat siku}

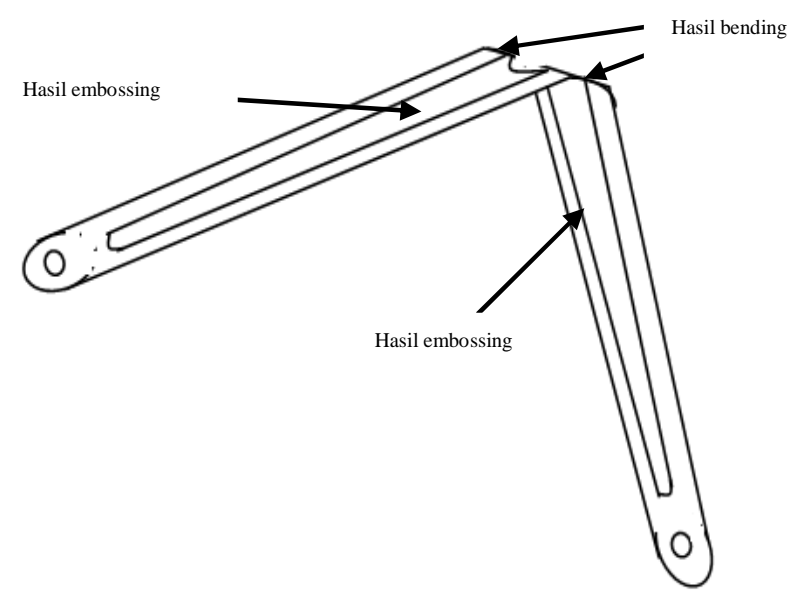

Gambar 3. Produk pelat siku penyangga 


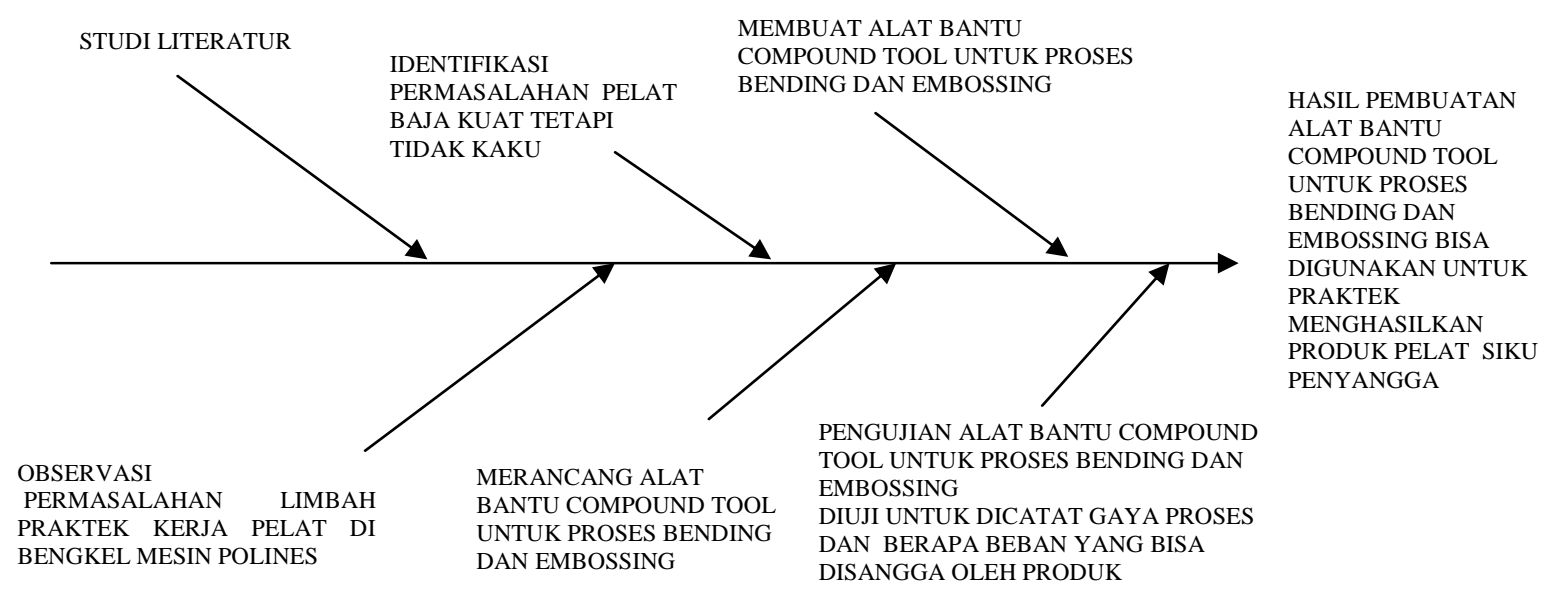

Gambar 4. Diagram Fishbone Penelitian

\section{Hasil dan Pembahasan}

\subsection{Hasil Raqncang Bangun Penelotian}

Rancang bangun compoud tool ini berupa alat bantu pembentukan proses embossing kerja pelat untuk membuat produk pelat siku penyangga.

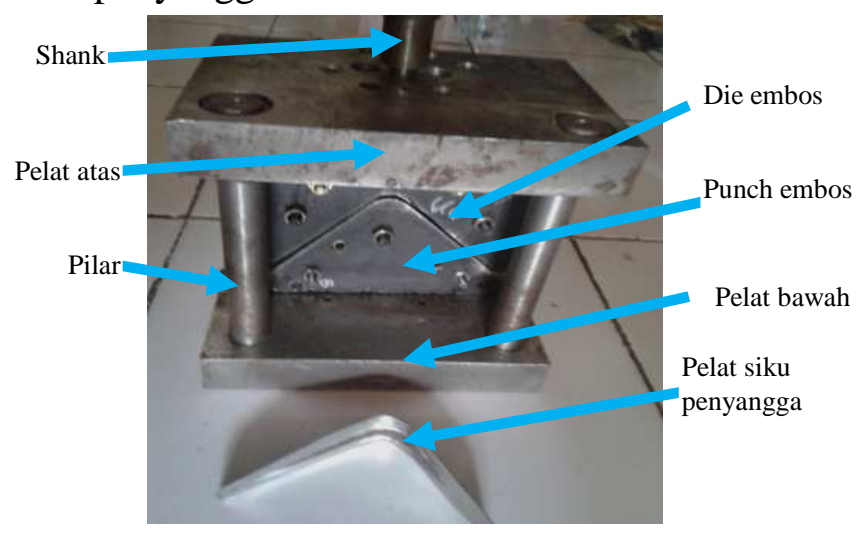

\section{Gambar 5. Alat bantu compound tool}

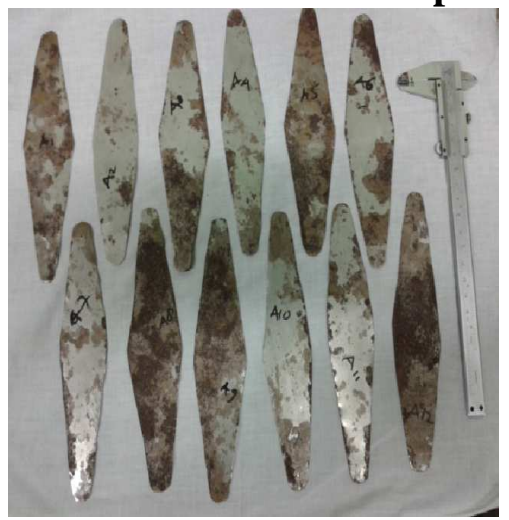

Gambar 6. Pelat bahan baku sebelum ditekuk

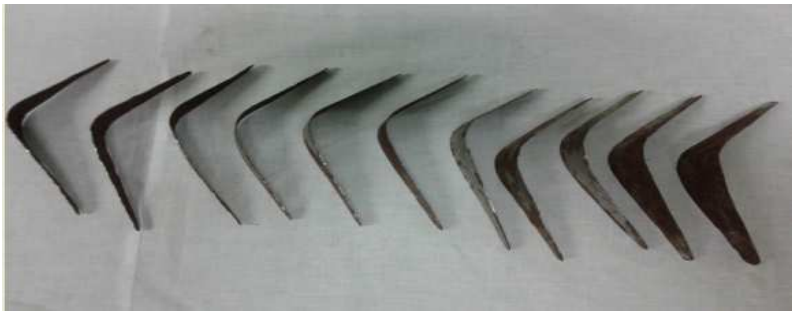

Gambar 7. Bahan baku ditekuk awal

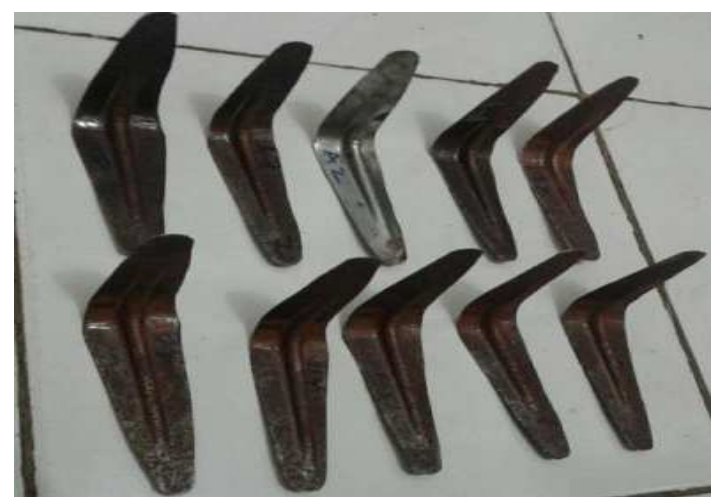

Gambar 8. Produk pelat siku penyangga telah di emboss dengan compound tool

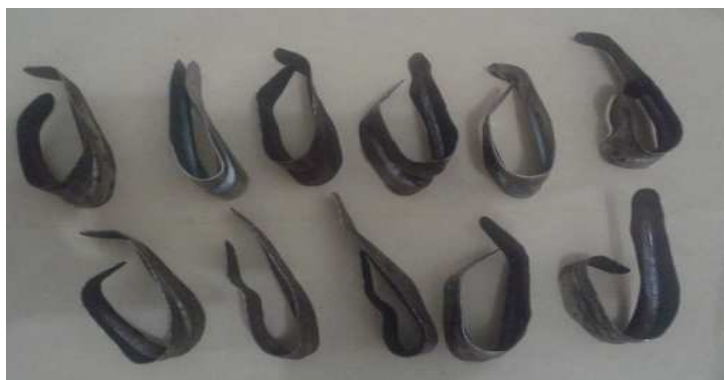

Gambar 9. Sampel uji pelat siku penyangga setelah di-emboss di uji kekuatan tekuk rusak. 
Pelat siku penyangga dibuat dari pelat baja tebal 0,7 mm, bahan baku ini berasal dari pelat baja low carbon setara dengan baja 37(dari bahan sisa-sisa praktek kerja pelat mahasiswa jurusan teknik mesin Polines, bahan sisa (waste material) ini biasanya dibuang begitu saja karena dianggap sudah tidak bisa dimanfaatkan. Compund tool (gambar 5) dari hasil penelitian ini mampu untuk mengolah pelat baja sisa praktek dijadikan produk pelat siku penyangga yang bisa dipergunakan untuk penyangga dudukan buku (gambar 8). Sebelum dibuat sampel uji produk pelat siku penyangga, bahan baku sampel uji pelat harus dipotong dibentuk blank (gambar 6) selanjutnya sampel uji yang berjumlah sepuluh berupa blank ditekuk membentuk siku dengan manual (gambr 7) agar mudah ditaruh di alat bantu compound tool. Sampel uji pelat yang sudah ditekuk dengan manual siap diuji dengan prosess embossing dengan alat bantu compound tool dengan memberi tekanan gaya emboss untuk dibentuk pelat siku penyangga yang kuat (gambar 8). Pelat siku penyangga dari hasil embossing yang sudah jadi perlu diuji sampai sejauh mana kekutannya dengan uji bending sampai menekuk $180^{\circ}$ (gambar 9).

Pengujian dari proses embossing didapat data gaya emboss-nya seperti pada tabel 1 , selain gaya emboss untuk membentuk pelat siku penyangga juga perlu dilakukan pengujian kekuatan tekuk sampai rusaknya pelat siku penyangga tersebut (gambar 9).

\subsection{Data Hasil Pengujian}

Tabel 1. Gaya Emboss Pengujian Sampel Uji

\begin{tabular}{lllll}
\hline $\mathbf{N O}$ & $\mathbf{F}_{\mathbf{E}}[\mathbf{N}\}$ & $\mathbf{B}_{\mathbf{O}}[\mathbf{m m}]$ & $\mathbf{B}_{\mathbf{U}}[\mathbf{m m}]$ & $\mathbf{F}_{\mathbf{U}}[\mathbf{N}]$ \\
\hline 1 & 15000 & 40 & 35,3 & 250 \\
2 & 20000 & 39 & 33 & 250 \\
3 & 20000 & 44 & 39 & 300 \\
4 & 22500 & 39 & 33,5 & 350 \\
5 & 25000 & 45 & 40 & 400 \\
6 & 27500 & 45 & 40 & 500 \\
7 & 27500 & 40 & 35 & 450 \\
8 & 30000 & 44 & 38 & 400 \\
9 & 32500 & 39,5 & 34 & 350 \\
10 & 35000 & $40 ?$ & 38 & 300 \\
\hline
\end{tabular}

Keterangan :

$\mathrm{F}_{\mathrm{E}}=$ Gaya yang diperlukan untuk embossing benda uji dalam satuan newton.

$\mathrm{F}_{\mathrm{U}}=$ Gaya pengujian kekuatan tekuk rusak sampel uji setelah di-emboss dalam satuan Newton.

$\mathrm{Bo}=$ Lebar benda uji awal dalam satuan milimeter

$\mathrm{Bu}$ - Lebar akhir setelah benda uji diemboss dalam satuan milimeter.

\subsection{Pembahasan Hasil Penelitian}

Dari data hasil pengujian seperti pada tabel 1, dapat dibuat grafik masing masing sampel uji sbb :

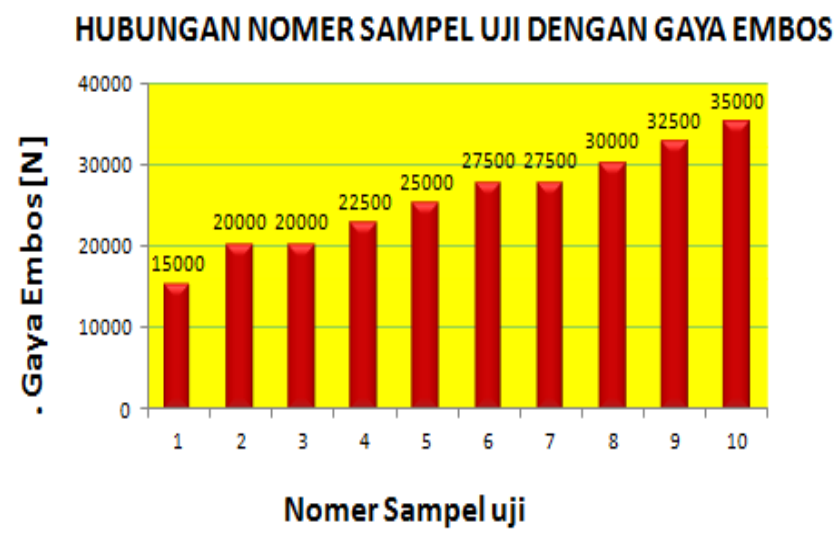

Gambar 10. Gaya embossing sepuluh sampel uji

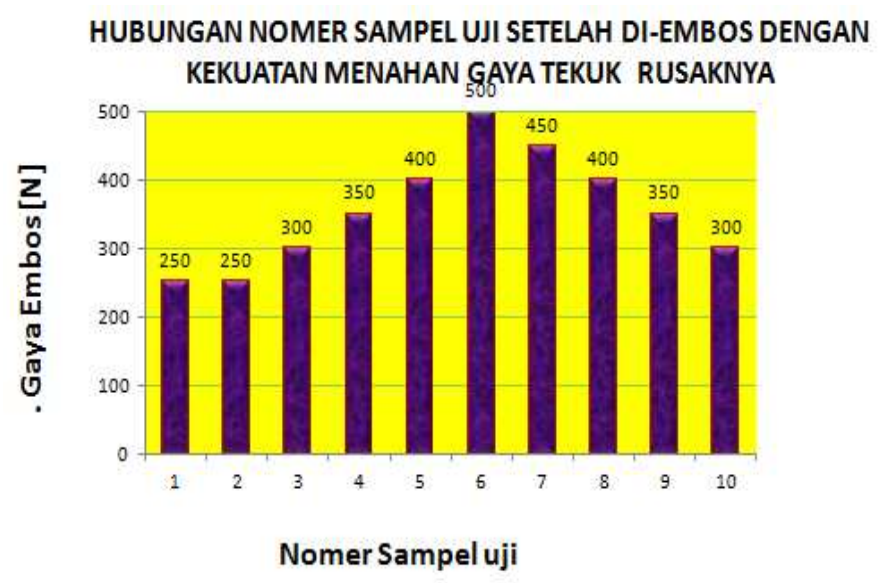

Gambar 11. Gaya kekuatan tekuk sampel uji setelah di-emboss 
Dari hasil pengujian sepuluh sampel uji dengan variasi gaya emboss dari $15000 \mathrm{~N}$ sampai $35000 \mathrm{~N}$ menunjukkan hasil sampel uji membentuk pelat siku penyangga yang sama bentuk fisiknya (gambar 23) namun setelah diuji kekuatan tekuknya hingga rusak menghasilkan gaya tekuk yang berbeda-beda. Gaya kekuatan tekuk rusak yang besar tidak pada sampel uji yang memerlukan gaya emboss yang kecil $(15000 \mathrm{~N})$ atau gaya emboss yang besar $(35000 \mathrm{~N})$ namun gaya tekuk rusak terting diperoleh dari sampell uji no.6 yang membutuhkan gaya emboss 27500 $\mathrm{N}$ dengan membutuhkan kekuatan gaya tekuk rusak sebesar $500 \mathrm{~N}$. Mengapa gaya tekuk rusak sampel uji yang membutuh kan gaya embos $27500 \mathrm{~N}$ yang menghasil kekuatan rusak terbesar bukan $15000 \mathrm{~N}$ atau $35000 \mathrm{~N}$, hal ini dapat disimpulkan karena gaya embooss $27500 \mathrm{~N}$ sampel uji no.6 merupakan bentuk sampel uji secara fisik yang baik bisa jadi sampel uji no.6 tidak mengalami deformasi plastis atau tidak mengalami keretakan walaupun peneliti tidak melalukan pengujian mikrogarafi. Dengan demikian dengan proses embossing pada pelat siku penyangga mampu meningkatkan kekuatan menahan beban/gaya tekuk sebesar $4900 \%$ dari kekuatan pelat siku penyangga yang tidak mengalami proses embossing yaitu dari $10 \mathrm{~N}$ (hasil pengujian sebelum uji embossing) meningkat menjadi $500 \mathrm{~N}$.

\section{Kesimpulan}

Luaran peenelitian ini berupa alat bantu Compound Tool untuk membuat produk pelat siku penyangga dari pelat bja low carbon sisa (waste material) praktek kerja pelat, dari hasil pengujian dapat disimpulkan sbb :
3. Compound tool mempunyai ukuran panjang $200 \mathrm{~mm}$, lebar $140 \mathrm{~mm}$ dan tinggi $200 \mathrm{~mm}$.

4. Sampel uji berupa pelat siku penyangga dudukan buku mempuyai ketebalan pelat 0,7 mm dari bahan baja low carbon dengan ukuran lebar $40 \mathrm{~mm}$,panjang 100 $\mathrm{mm}$, dan tinggi $80 \mathrm{~mm}$ dengan panjang garis emboss $84 \mathrm{~mm}$ dan $64 \mathrm{~mm}$.

5. Dari hasil pengujian dengan gaya embos dari 15000 sampai $35000 \mathrm{~N}$ menunjukan sampel uji dengan bentuk fisik yang baik dan sama dari 10 sampel uji.

6. Dari hasil pengujian kekuatan menahan gaya tekuk pada sampel uji pelat siku penyangga yang sudah di-emboss yang terbesar adalah sampel uji no.6 sebesar $500 \mathrm{~N}$ dengan gaya emboos $27500 \mathrm{~N}$.

7. Peningkatan kekuatan menahan gaya tekuk sampel uji pelat siku penyangga naik $4900 \%$ ( dari $10 \mathrm{~N}$ tanpa proses embossing dibandingkan $500 \mathrm{~N}$ dengan yang sampel uji yang mengalami proses embossing.

\section{Daftar Pustaka}

- Akhlis Rizza, Muhammad, 2014, Analisis Proses Blanking dengan Simple Press Tool Jurnal Rekayasa Mesin Vol.5, No.1 Tahun: 85-90

- Budiarto, 1997, Press Tool 1-3, Bandung, Politeknik Manufactur Bandung.

- Bubphachot, B., 2009, "Microstructure affecting cutting quality in fine blanking process", Am. J. Eng. Applied Sci., ISSN 0216-468X Vol.2, 665-668.

- Jutz, Herman dan Eduar Scharkus. 1976, Westermann Tables For The Material Trade. New Delhi: Wiley Eastern Ltd. 
- Suchy, Ivana, 1997, Hand Book of Die Design. New York, Mc Graw-Hill, Inc.

- Sularso \& Kiyokatsu Suga. 1978. Dasar Perancangan dan Pemilihan Elemen Mesin. PT. Pradnya Paramita: Jakarta.

- Suriyapha, Chatkew, Suthep, Y. dan Bubphachot, B., 2010, "Die Radius Affecting Sheet Metal Extrusion Quality for Fine Blanking Process",
American J. of Engineering and Applied Sciences, Vol.3.

- Rai, Pawan Kumar, Aas Mohammad, Hasan Zakir Jafri, 2013, "Causes \& Preventation of Defects (Burr) In Sheet Metal Component", International Journal of Engineering Research and Applications (IJERA) ISSN: 22489622, Vol. 3, Issue 4, Jul-Aug 2013, 511-515 